\title{
BIOLOGIA REPRODUTIVA DE FÊMEAS DE LAMBARI-PRATA, Astyanax scabripinnis Jenyns, 1842 (Characidae; Tetragonopterinae; Teleostei) EM CONDIÇÕES DE CATIVEIRO
}

\author{
Hélio Paulo Pereira Filho ${ }^{1,}$ Dalcio Ricardo de ANDRAde ${ }^{2}$, William CRistiane Teles Tonini ${ }^{3}$, \\ MANUEL VAZQUEZ VIDAL JR. ${ }^{1}$ \\ ${ }^{1}$ Professor Mestre, Universidade Federal de Viçosa, Viçosa, MG \\ ${ }^{2}$ Professor Doutor Universidade Estadual do Norte Fluminense Darcy Ribeiro, Campos de Goytacazes, RJ. - dalcio@uenf.br \\ ${ }^{3}$ Pesquisador Doutor da Universidade Estadual de Santa Cruz, Ilhéus, BA
}

\begin{abstract}
Estudou-se a biologia reprodutiva de Astyanax scabripinnis (lambari-prata) por meio do acompanhamento do desenvolvimento ovocitário de 94 fêmeas adultas. Foram feitas análises microscópicas dos ovários e dos índices gonadossomático, hepatossomático, de gordura visceral e fator de condição. As estruturas observadas nos ovários foram descritas a partir da análise histológica que, juntamente com o hepatossomático, foram utilizadas para determinar a participação do fígado no desenvolvimento dos ovócitos desta espécie. Ovogônias, ovócito tipo I e ovócito tipo II estiveram presentes em todos os estádios de desenvolvimento

gonadal. O ovócito que apresentou vesícula cortical esteve presente em grande quantidade no estádio intermediário de maturação (F2B) e em menor quantidade na fase final de maturação (F2C). Ovócitos maduros foram comuns no estádio intermediário de maturação (F2B), mas prevaleceram na fase final de maturação (F2C). Em animais desovados foram encontrados ovócitos em maturação final e maduros viáveis, muitos folículos atrésicos e pós-ovulatórios, além de desorganização do ovário, características definitivas da ocorrência de desova. Foram encontrados animais desovados por todo o ano, evidenciando que seja uma espécie de desova parcelada.
\end{abstract}

PALAVRAS-CHAVE: fígado; ovócitos; reprodução.

REPRODUCTIVE BIOLOGY IN FEMALES OF Astyanax scabripinnis Jenyns, 1842

(Characidae; Tetragonopterinae; Teleostei) UNDER CAPTIVITY CONDITIONS

\section{ABSTRACT}

We studied the reproductive biology of Astyanax scabripinnis by monitoring oocyte development of 94 adult females. Microscopic analysis of the ovaries, gonadosomatic and hepatosomatic indeces assessment, visceral fat and condition factor evaluations were carried out. The structures observed in the ovaries were described from the histological analysis and the hepatosomatic índex, which were used to determine the involvement of the liver in the development of oocytes of this species. Oogonia, oocyte I and oocyte II were present in all stages of gonadal development. Oocytes with cortical vesicles were present in large quantities in the intermediate stage of maturation (F2B) and in a lesser amount in the final stages of maturation (F2C). Mature oocytes were common in the intermediate stage of maturation (F2B), but prevailed in the final stages of maturation (F2C). Oocytes in final maturation and mature viable oocytes, many atresic and post-ovulation 
folicles were found in spawned animals, besides the ovary disorganization, which are strong characteristics of spawing. Spawned animals were found throughout

KEYWORDS: liver, oocyte; reproduction.

\section{INTRODUÇÃO}

O Brasil apresenta um dos maiores potenciais para a piscicultura, no cenário mundial, possuindo disponibilidade de recursos hídricos e extensão territorial com $75 \%$ de seu território em área tropical e uma ictiofauna rica em opções para a reprodução e criação em cativeiro (HAZIN, 2006).

Entre as espécies nativas, os lambaris do gênero Astyanax ssp. são espécies com potencial para a piscicultura, pois são peixes comumente utilizados como petisco e isca para a pesca esportiva. Em cultivo, aceitam rações artificiais, já sendo estudados e produzidos em cativeiro (HAYASHI et al., 2004; MEURER et al., 2005).

Sobre a espécie Astyanax scabripinnis Jenyns (1842), lambari-prata, há diversos trabalhos encontrados na literatura. BARBIERI (1992a) estudou a biologia populacional do $A$. scabripinnis paranae e BARBIERI (1992b) estudou os aspectos quantitativos da reprodução dessa espécie. MIZOGUCHI \& MARTINSSANTOS (1997 e 1998) estudaram genética de populações e citogenética de lambari-prata.

Buscando-se conhecer melhor a biologia reprodutiva de diferentes espécies e chegar a alguns parâmetros zootécnicos que auxiliem na reprodução em cativeiro, foram realizadas diversas pesquisas quanto à reprodução desses animais. ANDRADE et al., (1996) descreveram a espermatogênese da corvina Pachyurus squamipinnis; a morfologia microscópica do ovário e a citoquímica da zona pelúcida de lambari-bocarra Oligosarcus argenteus foram descritas por SANTOS et al. (1996) e NEVES et al. (1996), respectivamente; NOGUEIRA et al. (1997) estudaram a biologia reprodutiva anual de Bryconops cf. affinis, FÁVARO et al. (2003) descreveram os processos fisiológicos da reprodução do peixe-rei Atherinella brasiliensis e SOUZA et al. (2007) avaliaram os estádios de maturação gonadal em peixe-donzela, Stegastes fuscus, informações que proporcionaram a reprodução artificial dessas espécies. O interesse the year, showing that the species presents a kind of intermittent spawning. na análise morfológica das gônadas do Astyanax scabripinnis, lambari-prata, fundamenta-se na quase inexistência na literatura de dados sobre a biologia reprodutiva dessa espécie, indispensável para a definição de índices zootécnicos, necessários para a criação em cativeiro dessa e de qualquer espécie, além da necessidade de conhecimentos para efeito comparativo com outras espécies da mesma família (MIZOGUCHI \& MARTINS-SANTOS, 1997 e MIZOGUCHI \& MARTINS-SANTOS, 1998).

O Astyanax scabripinnis é uma espécie rústica, de pequeno porte e de fácil manejo. Tratase de um peixe amplamente encontrado na Bacia Hidrográfica do Rio Doce (parte integrante da grande Bacia do Leste) (NELSON, 1994; citado por MIZOGUCHI \& MARTINS-SANTOS,1998). Os lambaris aparentemente não apresentam problemas quando mantidos em cativeiro, com baixa mortalidade e rápido desenvolvimento zootécnico (NAVARRO et al., 2006). Além disso, por se reproduzirem em ambientes lênticos, podem ser utilizados para repovoamento de represas resultantes do barramento de rios. Podem ser também utilizados para criação com outras espécies de diferentes hábitos alimentares, uma vez que servem como espécies forrageiras, podendo ser criados com o objetivo de servir de iscas para as espécies carnívoras de pesque-pagues e nos empreendimentos de pesca esportiva (CASTRO \& ARCIFA, 1987).

O presente trabalho teve como objetivos principais, descrever morfológica e histologicamente a biologia reprodutiva de fêmeas de lambari-prata (Astyanax scabripinnis).

\section{MATERIAL E MÉTODOS}

Foram coletadas mensalmente 10 fêmeas sexadas, entre os meses de novembro de 1993 a outubro de 1994, retiradas de um tanque de terra $\left(200 \mathrm{~m}^{3}\right)$, localizado na Estação de Hidrobiologia e Piscicultura da Universidade Federal de ViçosaUFV/MG. Os animais foram acondicionados em sacos de plástico com água e oxigênio e 
transportados para o laboratório de Histologia e Embriologia do Departamento de Biologia Geral da Universidade Federal de Viçosa, onde foram realizados os registros de dados e as preparações histológicas.

Os peixes foram sacrificados por ruptura da coluna cervical, no ponto do opérculo. Após incisão ventral, os ovários, as vísceras e a gordura visceral foram retirados e pesados. De cada exemplar, foram registrados os seguintes dados biométricos: Comprimento - Total (CT) e Padrão (CP), em centímetro; e Peso - Corporal (PC), das Gônadas (PG), do Fígado (PF) e da Gordura Visceral (PGV), em gramas.

Os pesos foram obtidos utilizando-se uma balança Bosch S2000, com precisão de 0,001g. Os pesos ovarianos foram utilizados para calcular os índices gonadossomáticos (IGS), e os pesos das vísceras e da gordura visceral serviram de base para o cálculo dos indicadores das condições fisiológicas, como os índices hepatossomático, de gordura visceral e fator de condição.

Os ovários foram fixados em líquido de Bouin e processados rotineiramente para inclusão em parafina. Foram feitos cortes de $6 \mu \mathrm{m}$ de espessura em Micrótomo Reichert-Jung Histocut 2045. As preparações obtidas foram submetidas às seguintes técnicas de coloração (BEÇAK e PAULETE, 1976): hematoxilina-eosina (HE); Tricômico de Masson (TM), para evidenciar fibras colágenas; Tricômico de Gomori (TG), idem; e Fuccina-Resorcina (FR), para fibras elásticas.

A coloração padrão de rotina histológica hematoxilina-eosina (HE) foi utilizada para auxiliar na descrição das estruturas ovarianas e consequentes fases do desenvolvimento ovocitário por meio do uso de microscópio óptico. Os ovócitos tiveram seu diâmetro máximo medido com o uso de recursos do processador de imagens, equipado com o software Pro Image IV, acoplado ao fotomicroscópio. Foram medidos 30 ovócitos de cada fase histológica: ovócito jovem, ovócito pré-vitelogênico, ovócito com alvéolo cortical e ovócito maduro. Os valores obtidos com essas medições foram úteis para confirmar a classificação morfológica dos diferentes tipos de ovócitos.

Foram selecionadas preparações histológicas para as colorações específicas para fibras. Um total de 96 lâminas foram confeccionadas, 32 para cada coloração, abrangendo-se as 12 coletas e os 04 estádios do ciclo reprodutivo. Essas lâminas foram utilizadas para descrição morfológica das fases do desenvolvimento ovocitário e das demais estruturas ovarianas.

Para verificar diferenças significativas entre os valores obtidos para cada um dos índices, aplicou-se o teste de média $\mathrm{t}$ de Student, e estimaram-se as correlações entre os diversos índices, pela matriz de correlações de Pearson.

\section{RESULTADOS E DISCUSSÃO}

A morfologia macroscópica dos ovários de A. Scabripinnis, avaliada na presente pesquisa, segue o padrão descrito para a maioria dos teleósteos, sendo pares, alongados e foliáceos, sofrendo modificações na coloração, volume e espessura durante as diferentes fases do ciclo reprodutivo, semelhantes às de outras espécies de Astyanax, conforme descrito por MELO et al. (2005).

Semelhante ao descrito por LEONARDO et al. (2004) sobre surubim (Pseudoplatystoma fasciatum), observaram-se nesta pesquisa os estágios descritos para a maturação gonadal, inicialmente com a alta concentração de ovogônias, indicando sua proliferação, depois a diferenciação em ovócitos, seguidos de pequenas modificações morfológicas, ligadas ao processo de vitelogênese (COSTA et al., 2005). Esse processo envolve outros importantes órgãos do animal, como fígado, elevando seu peso durante a produção de vitelogenina e redução da gordura visceral, que é utilizada como fonte extra de energia, podendo ser observadas variações na composição e distribuição do vitelo, no grau de desenvolvimento dos alvéolos corticais e no desenvolvimento das camadas envoltórias dos ovócitos (BALDISSEROTTO, 2002). Em função das modificações supracitadas e observadas neste estudo, puderam-se classificar os estágios reprodutivos, por meio da visualização macroscópica dos ovócitos.

Após a proliferação e o início de diferenciação, as ovogônias transformam-se em ovócitos, possibilitando uma classificação em quatro fases de desenvolvimento, com base na análise histológica. Levaram-se em consideração, para efeito de classificação, as modificações morfológicas que ocorrem nos núcleos, citoplasmas e envoltórios dos ovócitos. O diâmetro do ovócito também contribuiu para essa classificação (BARRETO et al.,1998), visualizada na Figura 1 (a-d). 

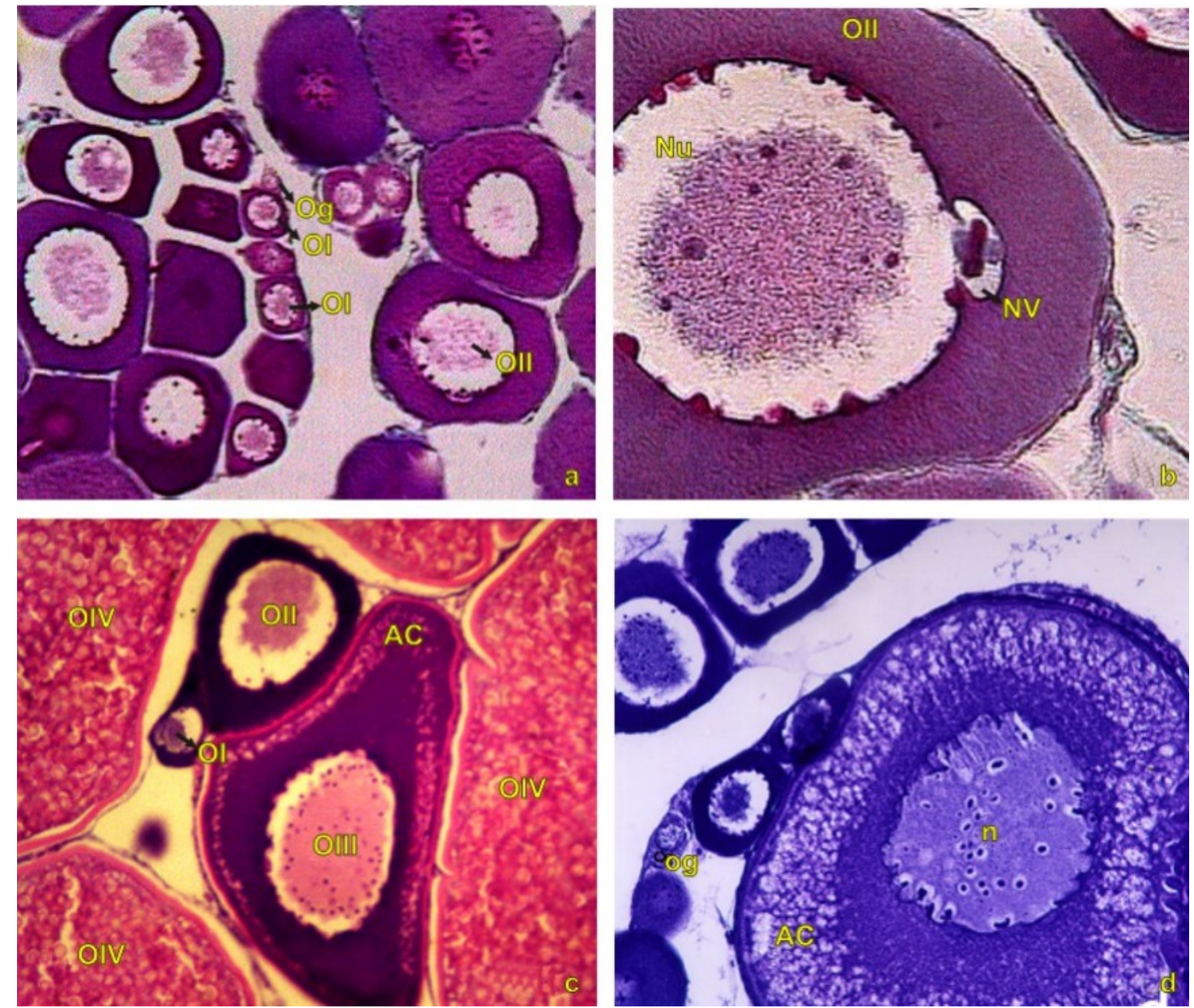

Figura 1 - Secções do ovário de lambari-prata, mostrando as variações morfológicas dos ovócitos: (a) ovócitos jovens (OI), ovócitos pré-vitelogênicos (OII) e ovogônia (Og), TM 400x. (b) Ovócito pré-vitelogênico (OII), com núcleo de contorno regular e material nuclear (nu) migrando para o citoplasma. Núcleo vitelínico (NV) TM 1000x. (c) Sequência mostrando as quatro fases morfológicas dos ovócitos: ovócito jovem (OI), ovócito pré-vitelogênico (OII), ovócito com alvéolo cortical (OIII), ovócito maduro (OIV). Na periferia do OIII, alvéolo cortical (AC). HE 400x; e (d) ovócito com alvéolo cortical (OIII). O alvéolo cortical (AC) expandido e a granulação do citoplasma indicando vitelogênese. À esquerda de OIII, uma ovogônia (Og). HE 400x.

Na fase ovócito jovem (OI - 100,693 $\mu \mathrm{m} \pm$ $5,876)$, os ovócitos apresentaram citoplasma acentuadamente basófilo, homogêneo, com aspecto vítreo, núcleo relativamente grande, hialino, esférico de diâmetro reduzido. A cromatina esteve distribuída por todo o nucleoplasma, entremeada por vários corpúsculos arredondados e basófilos. À medida que se apresentaram mais desenvolvidos, o citoplasma esteve menos homogêneo e menos basófilo. Os corpúsculos mostraram-se periféricos e aderidos ao envoltório nuclear, demonstrando uma clara migração de material nuclear para o citoplasma, provavelmente o primeiro passo da vitelogênese.
Na fase ovócito pré-vitelogênico (OII diâmetro de 168,788 $\mu \mathrm{m} \pm$ 6,537), observou-se redução da basofilia citoplasmática, em relação ao ovócito I. O citoplasma apresentou aspecto granular e com núcleo vitelínico. Essa estrutura é única, basófila e esférica, localizada na região justanuclear, circundada por um halo claro, que vai aos poucos sendo preenchido por material granular. Conforme o ovócito tornava-se mais maduro, o núcleo vitelínico (NV) aproximava-se mais do ooplasma periférico, fragmentando-se e formando um colar de grânulos, que antecede a formação do alvéolo cortical e o processo vitelogênico. 
O núcleo do ovócito II é grande e nele observa-se grande número de corpúsculos, que se localizam na periferia do mesmo, em íntimo contato com o envoltório nuclear. Nesse ovócito, já foi possível a nítida visualização da zona pelúcida (ZP), envolvendo todo o ovócito. Do lado externo à zona pelúcida, visualizaram-se as células foliculares pavimentosas.

O ovócito II bem como ovócito I e as ovogônias são encontrados em todos os estádios do ciclo reprodutivo.

A fase ovócito com vesículas corticais (OIII - diâmetro de 394,591 \pm m 7,397) foi caracterizada pela observação de estruturas claras e vacuolares, na periferia do ooplasma, formando as vesículas corticais que, em conjunto, formavam o alvéolo cortical (AC). Neste momento já foi possível a visualização de glóbulos de vitelo.

Observou-se que o núcleo desse ovócito apresentava-se grande, claro, basófilo e com cromatina granulosa irregular. $\mathrm{O}$ envoltório nuclear foi menos definido que na fase anterior. A zona pelúcida foi observada mais espessa com células foliculares pavimentosas. $\mathrm{O}$ aparelho micropilar foi verificado já nesta fase do ovócito.

Ovócitos vitelogênicos ou maduros (OIV diâmetro de $620,395 \mu \mathrm{m} \pm 13,146)$ foram encontrados em maior parte entre os meses de novembro a abril, sendo os maiores ovócitos observados. Apresentaram-se com quase toda a extensão ocupada por glóbulos de vitelo e, em decorrência disso, o alvéolo cortical estava restrito à camada mais externa do ooplasma, em contato com a membrana citoplasmática, não sendo possível ser distinguido. O ovócito se apresentou acidófilo em função do vitelo e o núcleo, quando visível, foi irregular, sem envoltório evidente, muitas vezes deslocado para o polo animal mais próximo do aparelho micropilar.

Neste estágio dos ovócitos, a zona pelúcida mostrava-se espessa, com estriações transversais, atingindo a espessura máxima em ovócitos viáveis. As células foliculares estavam pavimentosas sendo possível distinguir entre células da camada granulosa de origem epitelial e células das tecas de origem conjuntiva. Em alguns ovócitos IV, foi possível observar a passagem de células granulosas pavimentosas a cúbicas, pela mudança do formato de seus respectivos núcleos, de achatado a esférico. Acredita-se que esse envoltório possa intermediar a passagem de substancias para o interior do ovócito.

O aparelho micropilar é constituído de micrópila e uma célula micropilar constituída por um corpo e um prolongamento. O corpo ocupa o vestíbulo da micrópila e o prolongamento obstrui o canal micropilar. $\mathrm{O}$ aparelho micropilar foi observado a partir do ovócito II, sendo mais frequente e proeminente em ovócitos IV apresentando-se totalmente desenvolvido (a micrópila torna-se livre de sua célula micropilar, tornando o ovócito apto à fertilização) neste último estágio. Em ovócitos III, a célula micropilar é globosa, evoluindo para uma forma mais alongada, prismática, em ovócitos IV. A zona pelúcida em lambari-prata, na região da micrópila, apresentou-se mais espessa que o restante do ovócito.

A determinação do estágio de maturação dos ovócitos de peixes criados em cativeiro é essencial para os procedimentos de cultivo e de manejo reprodutivo. A identificação macroscópica dos estádios de maturação gonadal de fêmeas é amplamente utilizada para a descrição dos estágios reprodutivos de diversas espécies (VAZZOLER, 1996), sendo os ovários normalmente classificados em: imaturo (A), em maturação (B), maduro (C) e desovado (D), de acordo com a proporção de células maduras.

BARBIERI et al. (1981), com base na análise macroscópica, determinaram estádios de maturação gonadal para Geophagus brasiliensis da represa do Lobo, São Paulo. NOMURA (1975) também se baseou na análise macroscópica para determinar a curva de maturação gonadal para o gênero Astyanax, do rio Mogi-Guaçu, São Paulo, onde encontrou peixes com ovócitos maduros o ano todo, apresentando desova. MIRANDA et al. (1999) estudou o processo de atresia folicular de Astyanax bimaculatus lacustris como indicativo de período de desova. FAVARO et al. (2005) definiu a biologia reprodutiva de bagre amarelo (Cathorops spixii), por meio do acompanhamento do desenvolvimento dos ovócitos. VAZ-DOSSANTOS et al. (2005) estudaram indícios de primeira maturação gonadal de merluzas Merluccius hubbsi, por meio de observações macroscópicas.

O presente estudo também identificou fêmeas em atividade reprodutiva (estágio de ovócitos IV), durante todo o ano. Fêmeas sem a presença de ovócitos maduros ou em maturação foram registradas no período de abril a maio e também no mês de setembro. Ovários com maior número de ovócitos em desenvolvimento foram registrados nos períodos de novembro a fevereiro e de maio a julho.

Ovários maduros, prontos para a desova 
foram registrados no mês de novembro e nos períodos de janeiro a fevereiro e de junho a outubro. Ovários com sinais de desova e com uma grande quantidade de ovócitos do tipo IV foram registrados no mês de novembro e no período de janeiro a abril. Em nenhum mês do período analisado houve apenas ovócitos do tipo I ou II, sem a presença de ovócitos maduros (Figura 01c OIV).

A presença de ovários maduros (tipo IV) é utilizada em inúmeros trabalhos, como uma das principais ferramentas para se determinar o período de reprodução dos peixes, sendo a mais utilizada em casos de espécies com desovas intermitentes ou nas que desovam o ano todo (ANDRADE et al., 1985; TELES \& GODINHO, 1997; FERREIRA \& GODINHO, 1990; VAZZOLER \& MENEZES, 1992; TAVARES \& GODINHO, 1994; SANTOS et al., 1996; NOGUEIRA et al., 1997; BARRETO et al., 1998; e BAZZOLI et al., 1998; ANDRADE et al., 2010).

A utilização do IGS como indicador do desenvolvimento gonadal de peixes é comum na literatura, uma vez que gônadas com uma massa elevada em relação ao peso das espécies estão intimamente relacionados à maturidade sexual das mesmas (ANDRADE et al., 1996; BARBIERI \& BARBIERI, 1988; FERREIRA \& GODINHO, 1990; TAVARES \& GODINHO, 1994; FERREIRA et al., 1996; VAZZOLER, 1996; MIRANDA et al., 1999; BAZZOLI et al., 1997 (a e b); NOGUEIRA et al., 1997; TELES \& GODINHO, 1997; BARRETO et al., 1998; HOJO et al., 2004).

Como na maioria dos trabalhos citados acima, em A. scabripinnis, o IGS atingiu o pico na época de maturação avançada para depois decrescer até a época de desova tornando-se evidente que o desenvolvimento gonadal (BARRETO et al., 1998; GOITEIN \& LIMAJUNIOR, 2006; RIBEIRO, et al., 2007) ocorre em consonância com o aumento das gônadas e é diretamente proporcional ao crescimento do corpo do animal. O IGS pode ser considerado um dos melhores indicadores para a época de reprodução.

O IHS de A. scabripinnis foi decrescendo de repouso até maturação avançada dos ovócitos, quando atingiu valor mais elevado. Essa observação está de acordo com o fato de o fígado transferir proteína para compor o vitelo (TAVARES \& GODINHO, 1994; BARRETO et al., 1998; BARBIERI et al., 1982; FAVARO et al., 2005). Segundo WALLACE \& SELLMAN (1981) e BALDISSEROTTO (2002), proteínas sintetizadas pelo fígado são transportadas para o ovário, onde participam da formação do vitelo. Foi significativa a elevação dos valores de IHS durante o amadurecimento dos ovócitos, demonstrando o importante papel do fígado nos processos ligados à reprodução, provavelmente, fornecendo energia graças à quebra do glicogênio armazenado por esse órgão e, principalmente, o fornecimento de vitelogenina para a formação do vitelo, processo em que é, na sua maioria, exógena.

As fêmeas de lambari A. scabripinnis no estágio de repouso apresentaram maior acúmulo de gordura, sugerindo que, durante a fase que antecede a maturação gonadal, os peixes acumularam reservas energéticas para posterior utilização na fase de maturação (MIRANDA 1996). Quanto ao IGV, pode-se dividir a maturação em dois momentos: um primeiro momento, que engloba a maturação inicial, em que o IGV foi alto, indicando acúmulo de gordura, preparando o organismo para a reprodução e um segundo momento, com incremento da atividade reprodutiva, durante a maturação avançada, quando as reservas de gordura foram consumidas, pois a sua demanda energética nessa época é muito alta.

Os valores de IGV decaíram conforme ia ocorrendo a maturação dos ovócitos, confirmando a importante mobilização de gordura durante o processo reprodutivo. Essa mobilização é importante, pois alguns peixes diminuem a alimentação, ou mesmo param de se alimentar nos meses de intensa atividade reprodutiva. A gordura armazenada é usada como fonte de energia para o período reprodutivo e também fonte de matéria para a formação do vitelo.

Neste estudo, os valores de $\mathrm{K}$ para $A$. scabripinnis mostraram-se crescentes conforme a evolução da maturação ovocitária, quando atingiu seu maior valor, no mês de novembro (Figura 2). Isso demonstrou que as fêmeas estavam em boas condições fisiológicas, durante o período reprodutivo, tendo uma queda nessas condições durante a desova, o que é perfeitamente normal, pois o processo de desova é desgastante para o animal. 


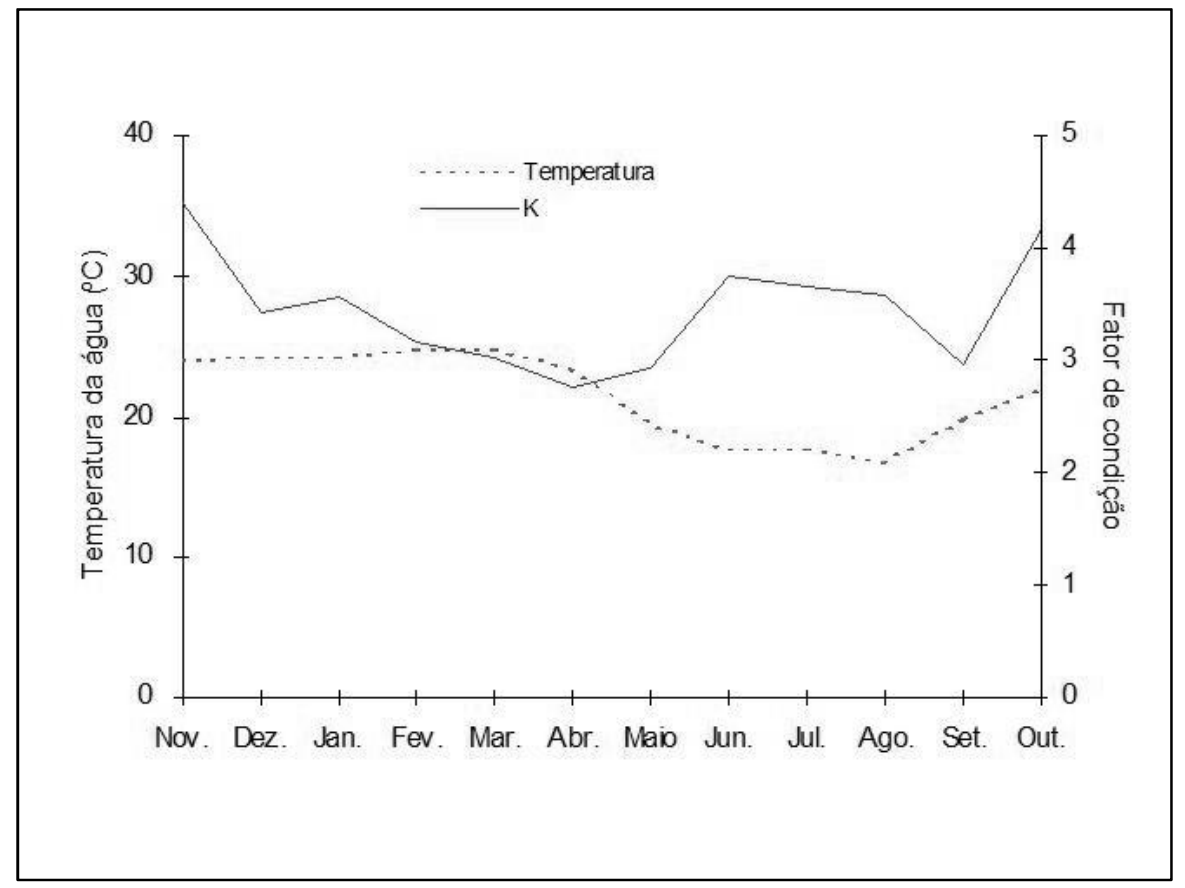

Figura 2 - Fator de condição (K) anual de Astianax scabripinnis e variação da temperatura média do ambiente de coleta.

\section{CONCLUSÕES}

O lambari-prata apresentou atividade reprodutiva em todo o período estudado, assim como demonstrado pelos estágios de maturação gonadal. Verificaram-se fêmeas desovadas durante todo o ano, apresentando desova do tipo parcelada, demonstrando ser uma espécie de desenvolvimento ovocitário assincrônico. O período de maturação máxima dos ovócitos e a presença de folículos vazios ocorreram entre novembro e abril, coincidindo com temperaturas mais elevadas, maior precipitação pluviométrica e dias mais longos, indicando possivelmente o período de maior atividade reprodutiva ao longo do ano.

\section{REFERÊNCIAS}

ANDRADE, R.F.; SATO, Y.; RIZZO, E.; FERREIRA, R.M. A.; BAZZOLI, N. Aspectos da biologia reprodutiva da corvina Pachyurus squamipinnis Agassiz, 1829 (Teleostei, Sciaenidae) na represa de Três Marias, MG. Arquivo Brasileiro de Medicina Veterinária e Zootecnia, v.48, n.01, p. 77-84, 1996.

ANDRADE, D.R.; VIDAL JUNIOR, M.V.; GODINHO, H.P.; TONINI, W.C.T.; BURKET. D. Fecundidade da manjuba Curimatella lepidura (CURIMATIDAE) na represa de Três Marias, rio São Francisco, MG. Arquivo Brasileiro de Medicina Veterinária e Zootecnia, v.62, n.6, p.1401-1408, 2010.
ANDRADE, D.R.; GODINHO, H.P.; RIBEIRO, S.P.; CASTRO, E.F.T. Ciclo reprodutivo de lambaris (Astyanax bimaculatus Linnaeus, 1758) em viveiros. Arquivo Brasileiro de Medicina Veterinária e Zootecnia, v.37, n.5, p. 435-447, 1985.

BALDISSEROTTO, B. 2002. Fisiologia de peixes aplicada à piscicultura. Santa Maria: Ed.UFSM. RG. 212p.

BARBIERI, G. Biologia de Astyanax scabripinnis paranae (Characiformes, Characidae) do ribeirão do Fazzari. São Carlos. Estado de São Paulo. I. Estrutura populacional e crescimento. Revista Brasileira de Biologia, v.52, n.4, p. 579-588, 1992a.

BARBIERI, G. Biologia de Astyanax scabripinnis paranae (Characiformes, Characidae) do ribeirão do Fazzari. São Carlos. Estado de São Paulo. II. Aspectos quantitativos da reprodução. Revista Brasileira de Biologia, v.52, n.4, p. 589-596, 1992 b.

BARBIERI, G.; BARBIERI, M.C. Curva de maturação, tamanho de primeira maturação gonadal e fecundidade de Astyanax bimaculatus e Astyanax fasciatus, da represa do Lobo, estado de São Paulo (Osteichthyes, Characidae). Revista Ceres, v.35, n.197, p. 64-67, 1988.

BARBIERI, G.; SANTOS, M.V.R.; SANTOS, J.M. Época de reprodução e relação peso/comprimento de duas espécies de Astyanax (Pisces, Characidae). Pesquisa Agropecuária Brasileira, v.17, n.7, p.1057-1067, 1982.

BARBIERI, M.C.; BARBIERI, G.; MARINS, M.A. Sobre a anatomia e histologia de ovário de Geophagus brasiliensis (Quoy e Gaimard, 1824) na Represa do Lobo, estado de São Paulo. Revista Brasileira de Biologia, 
v.41, n.01, p. 163-168, 1981.

BARRETO, B.P.; RATTON, T.F.; RICARDO, M.C.P.; ALVES, C.B.M.; VONO, V.; VIEIRA, F.; RIZZO, E.; BAZZOLI, N. Biologia reprodutiva do lambari Astyanax bimaculatus (Pisces, Characidae) no rio do Carmo, bacia do rio Grande, São Paulo. Bios, v.6, n.6, p. 121-130, 1998.

BAZZOLI, N.; CANGUSSU, L.C.V.; RIZZO, E.; SANTOS, G.B. Reprodução e desova de mandis Pimelodus maculatus e Lheringichthys labrosus (Pisces, Pimelodidae) nos reservatórios de Furnas, Maribondo e Itumbiara. Bios, v.5, n.5, p. 7-15, 1997 (a).

BAZZOLI, N.; SATO, Y.; SANTOS, J.E.; CRUZ, A.M.G.; CANGUSSU, L.C.V.; PIMENTA, R.S.; RIBEIRO, V.M.A. Biologia reprodutiva de quatro espécies de peixes forrageiros da represa de Três Marias, MG. Bios, v.5, n.5, p. 17-28, 1997 (b).

BAZZOLI, N.; MESQUITA, T.L.; SANTOS, G.B.; RIZZO, E. Análise comparativa da reprodução de Astyanax bimaculatus (Pisces, Characidae) nos reservatórios de Furnas, Marimbondo e Itumbiara. Bios, v.6, n.6, p. 99-112, 1998.

BEÇAK, W.; PAULETE, J. Técnicas de citologia e histologia. Rio de Janeiro: Livros Técnicos e Científicos, 1976. 412p.

CASTRO, R.M.C.; ARCIFA, M.S. Comunidade de peixes de reservatórios no sul do Brasil. Revista Brasileira de Biologia, v.47, n.4, p. 493-500, 1987.

COSTA, A.P.R.; ANDRADE, D.R.; VIDAL JUNIOR, M.V.; SOUZA G. Indicadores quantitativos da biologia reprodutiva de fêmeas de piau-vermelho no Rio Paraíba do Sul. Pesquisa Agropecuária Brasileira, v.40, n.8, p.789-795, 2005.

FÁVARO, L.F.; FREHSE, F.A.; OLIVEIRA R.N.; JÚNIOR, R.S. Reprodução do bagre-amarelo Cathorops spixii (Agassiz) (Siluriformes, Ariidae), na Baía de Pinheiros, região estuarina do litoral do Paraná, Brasil. Revista Brasileira de Biologia, v.22, n.4, p. 1022-1029. 2005.

FÁVARO, L.F.; LOPES, S.C.G; SPACH, H.L. Reprodução do peixe-rei Atherinella brasiliensis (Atheriniformes, Atherinidae), em uma planície de maré adjacente à gamboa do Baguaçu, Baía de Paranaguá, Paraná, Brasil. Revista Brasileira de Biologia, v.20, n.3, p. 501-506. 2003.

FERREIRA, R.M.A.; BAZZOLI, N.; RIZZO, E.; SATO, Y. Aspectos reprodutivos da piranha, Pygocentrus piraya (Teleostei, Characiformes), espécie nativa da bacia do rio São Francisco. Arquivo Brasileiro de Medicina Veterinária e Zootecnia, v.48, n.1, p. 71-76, 1996.

FERREIRA, R.M.A., GODINHO, H.P. Reproductive biology of the white-piau, Schizodon knerii (Steindachner, 1875) (Anostomidae) from a reservoir in southeast Brazil. Europe Archives Biology, v.101, p. 331-344, 1990.

GOTEIN, R. \& LIMA-JUNIOR, S.E. Fator de condição e ciclo gonadal de fêmeas de Pimelodus maculatus
(Osteichthyes, Pimelodidae) no rio piracicaba (SP, Brasil). Boletim Instituto de Pesca, São Paulo, v.32, n.1, p. 8794, 2006.

HAYASHI, C.; MEURER, F.; BOSCOLO, W. R.; LACERDA, F.C.H.; KAVATA, L.C.B. Freqüência de Arraçoamento para Alevinos de Lambari do RaboAmarelo (Astyanax bimaculatus). Revista Brasileira de Zootecnia, v.33, n.1, p. 21-26, 2004.

HAZIN, F.H.V. A pesca na zona econômica exclusiva, ZEE: sua importância para o Brasil. Revista Brasileira de Engenharia de Pesca, v.1, n.1, p. 10-18, 2006.

HOJO, R.E.S., SANTOS, G.B., BAZZOLI, N. Reproductive biology of Moenkhausia intermedia (eigenmann) (Pisces, Characiformes) in Itumbiara Reservoir, Goiás, Brazil. Revista Brasileira de Zoologia, v.21 n.3, p. 519-524, 2004.

LEONARDO, A.F.G.; ROMAGOSA, E.; BATLOUNI, S.R.; BORELLA, M.I. Characterization and hormonal efficiency in female cachara, Pseudoplatystoma fasciatum (Linnaeus, 1766), kept in captivity. Aquaculture, v.42, p. 451-461. 2004.

MELO, F.C.S.A.; MALDONADO, I.R.S.C.; BENJAMIN, L.A.; MATTA, S.L.P. Biologia reprodutiva de fêmeas de lambari-prata Astyanax scabripinnis (Chacaridae, Tetragonopterinae) em tanques de piscicultura. Revista Ceres. Viçosa. MG, v.52, n.304, p. 811-829, 2005.

MEURER, F.; HAYASHI, C.; BOSCOLO, W.R.; KAVATA, L.B.; LACERDA, C.H.F. Nível de Arraçoamento para Alevinos de Lambari-do-RaboAmarelo (Astyanax bimaculatus). Revista Brasileira de Zootecnia, v.34, n.6, p.1835-1840, 2005.

MIRANDA, A.C.L.; BAZZOLI, N.; RIZZO, E.; SATO, Y. Ovarian follicular atresia in two teleost species: a histological and ultrastructural study. Tissue \& Cell, v.31, n.5. P. 480-488. 1999.

MIZOGUCHI, S.M.H.N.; MARTINS-SANTOS, I.C. Cytogenetic and morphometric differences in populations of Astyanax scabripinnis (Pisces, Characidae) from Maringá region, PR, Brazil. Genetics and Molecular Biology, v. 21, n.1, p. 55-61, 1998.

MIZOGUCHI, S. M. H. N., MARTINS-SANTOS, I.C. Macro-and microchromosomes B in females of Astyanax scabripinnis (Pisces, Characidae). Hereditas, v. 127, n. 3, p. 249-253, 1997.

NAVARRO R. D.; SILVA R. F.; RIBEIRO FILHO O. P.; CALADO L.L.; REZENDE F.P.; SILVA C.S.; SANTOS L.C. Comparação morfometrica e índices somáticos de machos e fêmeas do lambari prata (Astayanax scabripinnis Jerenyns, 1842) em diferente sistema de cultivo. Zootecnia Tropical, v. 24, n.2, p. 165-176. 2006.

NEVES, C. A., ANDRADE, D. R., MATTA, S. L. P., VIDAL-JÚNIOR, M. V., SANTOS, A. A. The zona pellucida of the freshwater fish Oligosarcus argenteus Gunther (Pisces, Characidae): a cytochemical study. Arquivo Brasileiro de Medicina Veterinária e 
Zootecnia, v. 48, n. 1, p. 25-32, 1996.

NOGUEIRA, B.P., BAZZOLI, N., SANTOS, J.E., BARROS, M.D.M. Biologia reprodutiva de Bryconops $c f$. affinis = Creatochanes affinis (Gunther, 1864) (Teleostei: Characiformes) na lagoa do Pantaninho, Lagoa da Prata, Minas Gerais. Bios, v.5, n.5, p. 43-51, 1997.

NOMURA, H. Fecundidade, maturação sexual e índice gônado-somático de lambaris do gênero Astyanax Baird \& Girard, 1854 (Osteichthyes, Characidae), relacionados com fatores ambientais. Revista Brasileira de Biologia, v. 35, n.4. p: 775-798, 1975.

SANTOS, G.B., BARROS, L.N.V., MENEZES, M.U. Fecundity of the Astyanax bimaculatus (Reinhardt, 1874). (Teleostei, Characidae) from uper Rio São Francisco basin, Brazil. Arquivo Brasileiro de Medicina Veterinária e Zootecnia, v.48, n.1, p. 101-108, 1996.

SOUZA, L.L.G.; CHELLAPPA, S.; GURGEL, H.C.B. Biologia reprodutiva do peixe-donzela, Stegastes fuscus Cuvier, em arrecifes rochosos no nordeste do Brasil Revista Brasileira de Zoologia. v.24, n.4, p. 419-425, 2007.

RIBEIRO, V.M.A.; SANTOS, G.B.; BAZZOLI, N. Reproductive biology of Steindachnerina insculpta (Fernandez-yépez) (Teleostei, Curimatidae) in Furnas Reservoir, Minas Gerais , Brazil. Revista Brasileira de Zoologia, v.24 n.1, p.71-76, 2007.
TAVARES, E.F.; GODINHO, H.P. Ciclo reprodutivo do peixe piau-gordura (Leporinus piau Fowler, 1941) da represa de Três Marias, rio São Francisco. Revista Ceres, v.41, n.233, p. 28-35, 1994.

TELES, M.E.O.; GODINHO, H.P. Ciclo reprodutivo da Pirambeba Serrasalmus brandtii (Teleostei, Characidae) na represa de Três Marias, rio São Francisco. Revista Brasileira de Biologia, v.57, n.2, p.177-184, 1997.

VAZ-DOS-SANTOS A.M.; HONJI R.M.; ROSSIWONGTSCHOWSKI C.L.D.B. Comprimento e idade de primeira maturação gonadal de fêmeas de merluza Merluccius hubbsi marini, 1933 na região sudeste-sul do Brasil. Boletim do Insituto de Pesca, São Paulo, v.31, n.2, p.109-117, 2005.

VAZZOLER, A.E.A.M. Biologia da reprodução de peixes teleósteos: teoria e prática. Maringá-PR: EDUEM, 1996, 169p.

VAZZOLER, A.E.A.M.; MENEZES, N.A. Síntese de conhecimentos sobre o comportamento reprodutivo dos characiformes da América do Sul (Teleostei, Ostariophysi). Revista Brasileira de Biologia, v.52, n.4, p. 627-640,1992.

WALLACE, R.A.; SELLMAN, K. Celular and dynamic aspects of oocyte growth in teleosts. American Zoology, v.21, n.2, p. 325-343, 1981.

Protocolado em: 29 out. 2007 Aceito em: 25 out. 2011. 